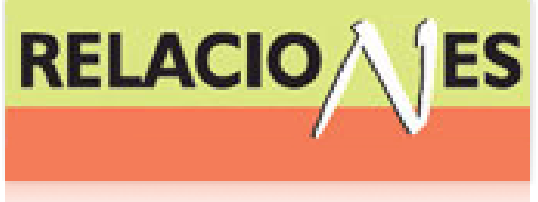

Relaciones. Estudios de historia y sociedad ISSN: 0185-3929

relacion@colmich.edu.mx

El Colegio de Michoacán, A.C

México

Espinosa Martínez, Edgar Iván

En busca de un método: la escritura de la historia en México, 1853-1889

Relaciones. Estudios de historia y sociedad, vol. XXXI, núm. 123, 2010, pp. 21-58

El Colegio de Michoacán, A.C

Zamora, México

Disponible en: http://www.redalyc.org/articulo.oa?id=13715893002

- Cómo citar el artículo

- Número completo

- Más información del artículo

Página de la revista en redalyc.org

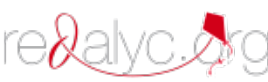

Sistema de Información Científica

Red de Revistas Científicas de América Latina, el Caribe, España y Portugal Proyecto académico sin fines de lucro, desarrollado bajo la iniciativa de acceso abierto 


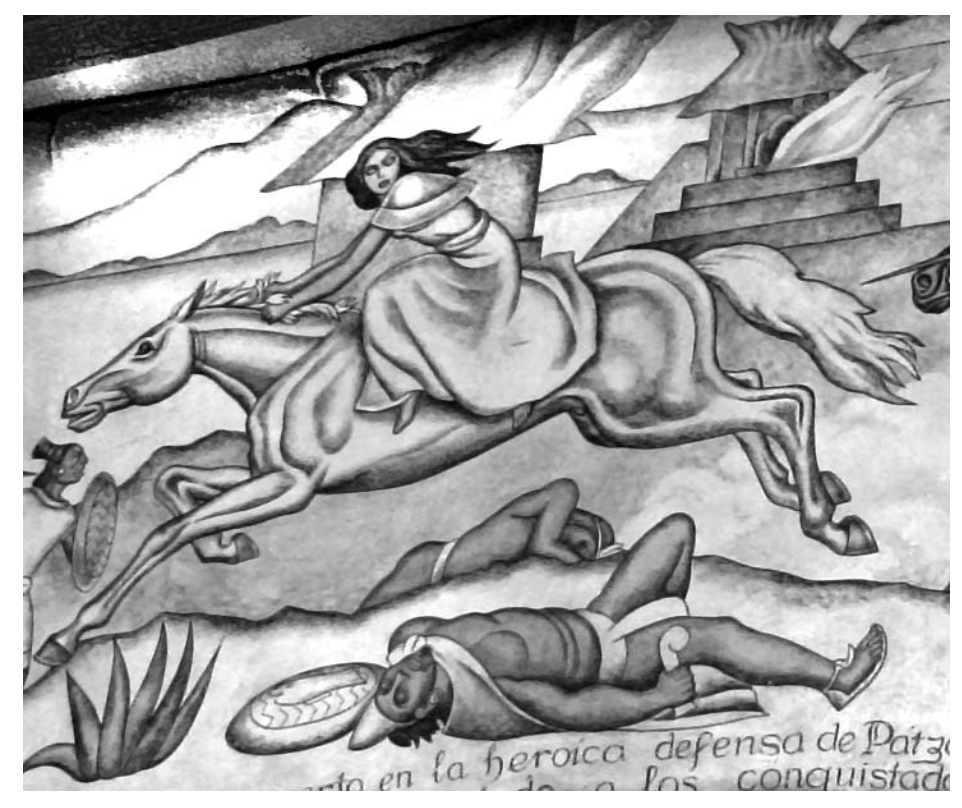

SECCIÓN Z EMÁtICA 


\title{
EN BUSCA DE UN MÉTODO: \\ LA ESCRITURA DE LA HISTORIA EN MÉXICO, 1853-1889
}

\section{Edgar Iván Espinosa Martínez*}

\begin{abstract}
El artículo muestra la forma en la cual se desarrolló una nueva forma de apropiación y de representación del pasado en México durante la segunda mitad del siglo XIX. Parar ello, se presenta el ámbito cultural y político que privó en el país durante dicho lapso; así, se pone énfasis en las tendencias y corrientes de pensamiento (en particular el romanticismo y el cientificismo) que influyeron en la escritura de la historia propuesta por más conspicuos hombres públicos de la época. Ello constituyó la plataforma para el estudio del pasado con un carácter nacional (representar a los mexicanos), espíritu liberal (guía de un Estado rector) y aspiración científica (historia lineal y documentalista).
\end{abstract}

(Ilustrado, romanticismo, cientificismo, escuela metódica)

La severa imparcialidad de la historia debe juzgar á los hombres y á los acontecimientos, sin preocuparse del efecto que su fallo ha de producir en las presentes ó venideras generaciones. El tribuno puede halagar las pasiones ó los intereses de la multitud para alcanzar el triunfo de una causa; el diplomático cubrir con un velo ante un gobierno los acontecimientos cuyos contornos le conviene que no se perciban; el poeta alzar sobre un pedestal de gloria al hombre que le inspira un canto. El historiador no puede ni debe más sino decir la verdad; pero como esa verdad iluminada por la filosofía del escritor afecta muchas veces formas y proporciones que están muy lejos de ser ciertas, preciso es alumbrar cada uno de los cuadros con la luz que es propia. Si quiere juzgarse á los hombres del siglo Xvı por el código de Ilustración, de cultura y de ciencia, que rige en el que alcanzamos; si las pasiones religiosas y políticas de la época de Carlos V; si los hechos, las leyes y las

* espinosa_edgarivan@yahoo.com.mx 
costumbres de aquellos tiempos se estudian con la antorcha que guía al mundo en los últimos años del siglo XIx, fallo injusto sería sin duda el que se pronuncie, y los personajes quedarán tan desconocidos para el lector como los hechos de esos grandes personajes serían para ellos mismos si pudieran leer las crónicas de su vida escritas bajo este sistema.

Vicente Riva Palacio

xisten investigaciones que desde hace unos lustros definen el campo de investigación historiográfica que ha tomado como objeto de estudio la propuesta de los historiadores del siglo XIX. Desde el rescate de escritos que ha ocurrido a partir de los años sesenta (Ortega y Medina) y en los noventa (Ruedas de la Serna), hasta el cúmulo de libros y artículos que sobre el tema han aparecido en los últimos lustros (Florescano Zermeño, Pi-Suñer, Rozat, Luna Argudín, Ortiz Monasterio), ofrecen un consenso en cuanto a detectar nuevas posturas metodológicas en dicha escritura. ${ }^{1}$ En líneas generales, son tres las aportaciones en el citado campo historiográfico que reclaman nuestra atención: a) profundizar el vínculo con otras disciplinas (filosofía, sociología, antropología, lingüística); b) asimismo, dichas conexiones permiten ubicar y trabajar con nuevas problematizaciones (cambios, contingencias, discontinuidades); c) al propio tiempo, los trabajos desarrollan un enfoque que pondera al personaje, su obra y su época como circunstancias concretas vinculadas entre sí.

Es el último aspecto señalado el que resulta de utilidad para desarrollar el argumento del presente trabajo; esto es, detectar el ámbito desde

${ }^{1}$ Véase Enrique Florescano, El nuevo pasado mexicano, 1991; Antonia Pi-Suñer Llorens, En busca de un discurso integrador de la nación, 1848-1884, 1996; Guy Rozat, Los orígenes de la nación, 2001; Guillermo Zermeño, La cultura moderna de la historia, 2002; María Luna Argudín, "La escritura d la historia y la tradición retórica (1834-1885)", 2004; José Ortiz Monasterio, México eternamente, 2004. Asimismo, la compilación Polémicas y ensayos mexicanos en torno a la historia realizada por Juan A. Ortega y Medina en 1970 permite apreciar la riqueza y profundidad de los debates que sobre teoría de la historia se desarrollaron en México entre 1824 y 1936. Del mismo modo, Jorge Ruedas de la Serna reunió en 1996 varios textos en La misión del escritor donde se advierte sobre la función social del escritor en el siglo XIX y la forma en que dicho segmento lo asumió. 
el cual se proyectaron propuestas modernas para el estudio de la historia nacional durante un lapso de la segunda mitad del siglo xIx en México. Así, la hipótesis del presente artículo indicaría que entre los historiadores mexicanos se tiene una tradición en cuanto a la concepción, el estudio y la escritura de la historia con carácter inédito. Entre dichos autores consideramos a Manuel Larrainzar, José Tomás de Cuellar, José María Vigil, José María Iglesias y Vicente Riva Palacio, por ser algunos de los personajes nacionales más citados y estudiados. Se toman en cuenta ciertos planteamientos que sobre la historia expresaron dichos personajes presentados como intentos dirigidos a crear una práctica metódica del oficio.

Dicha tradición historiográfica ha sido objeto de debate y reflexión por parte de los historiadores profesionales en sus investigaciones desde mediados del siglo Xx. Y de esas discusiones se retoma la idea que señalaban aquellos ilustrados respecto a la historia y a la historiografía como operaciones distintas según el criterio decimonónico de objetividad, que era mediado tanto por el documento como por el tiempo. Se pretende, entonces, problematizar sobre las prácticas que acompañaron al oficio en el lapso señalado.

\section{El LUGAR SOCIAL}

Se pretende advertir que existe en el país una tradición en torno a una propuesta historiográfica moderna desarrollada durante el siglo XIX. Por tanto, se sugiere que en dichos planteamientos están presentes los inicios de un debate para dotar a la historia de un esquema de trabajo metódico, organizado y sistemático. ¿Y quiénes eran esos hombres que se preocuparon por ello?, ¿qué ocupaciones tenían?, ¿cuál fue el tipo de educación que tuvieron?, ¿qué posición del tipo político-ideológico guardaron y defendieron? Los aspectos anteriores quedan definidos en lo que Michel de Certeau designó como el lugar social; esto es, el ámbito desde el cual se escribe y produce la escritura de la historia. ${ }^{2}$

${ }^{2}$ Michel de Certeau, La escritura de la historia, 1993, 68. Inspirado en un "despertar epistemológico" propiciado y promovido por autores como Moscovici, Foucault y Vey- 
Se apela al término ilustrado para referir a la elite que conformaban los profesionistas cuyo quehacer público abarcó distintos rubros como el académico, el político, el intelectual y el científico. Si bien tal concepto hace alusión al movimiento de la Ilustración desatado en Francia en los confines del siglo XVIII, sus ideas y preceptos llegaron y se arraigaron en México a los largo de la siguiente centuria. Así, aspectos como el raciocinio o lo científico permanecen presentes en los postulados de esas generaciones de eruditos. Puede decirse, entonces, que el impacto de dicho movimiento se deja sentir entre la elite intelectual mexicana durante el siglo XIX. ${ }^{3}$

Así, encontramos que los ilustrados decimonónicos, ocupados en profesiones reconocidas ahora como liberales y ejercidas particularmente en entornos urbanos (periodistas, literatos, abogados, ingenieros, médicos), habrían empezado una reflexión en dos sentidos: por un lado, la posibilidad de practicar una investigación y escritura de la historia que se alejara de meras preocupaciones estilísticas o especulaciones filosóficas; por otro, que la historia como disciplina pasara a formar parte de las ciencias modernas. Aquellas generaciones plantearon de forma estratégica una búsqueda, organización y crítica de documentos (método) para elaborar una representación de "verdad histórica" (escritura), que se caracterizó por un sentido ético (carácter cívico) y un uso político-ideológico (identidad nacional mexicana). Lo anterior advierte la existencia de un ámbito desde el cual se inició una nueva etapa en la tradición historiográfica mexicana.

Por ello, el análisis historiográfico propuesto apela al concepto de lugar social desarrollado por Michel de Certeau. El historiador jesuita

ne, el historiador jesuita francés se pregunta por las "condiciones previas" las cuales establecen leyes y referentes que definen y organizan el actuar y la producción de los historiadores en un ámbito determinado.

${ }^{3}$ Erika Pani señala que la "clase política" y los "hombres públicos" del siglo xIX en México fueron "herederos de la Ilustración y de las revoluciones atlánticas". Y una constante en dicho proceso fue "tratar de asimilar, amoldar y depurar" dicho legado ideológico. En el terreno de las ideas, aquellos ilustrados-entre los cuales se encuentra nuestro personaje-crearon a partir de ese influjo una postura intelectual y académica propia según las condiciones sociales y políticas de la sociedad mexicana de la época. Véase Erika Pani, Para mexicanizar el Segundo Imperio, 2001, 26. 
francés argumenta que en toda operación historiográfica se distingue un lugar, practicas científicas y una escritura. ${ }^{4} \mathrm{~A}$ partir de tal planteamiento se abordarán los siguientes aspectos: a) el "ámbito" (lugar social) desde el cual algunos prominentes miembros de la elite ilustrada se desempeñaron como historiadores, y b) el método (prácticas científicas) que dichos personajes propusieron y emplearon para el estudio del pasado (escritura) de forma científica.

Consideramos que desde ese "ámbito" se plantearon propuestas dirigidas a resolver problemáticas como reinventar a la nación para sustentar desde lo ideológico el proyecto de un Estado fuerte, la necesidad de convertir en ciudadanos a los mexicanos de la época a partir del conocimiento sobre ciertos sucesos y personajes, así como la decisión de desmarcar a la historia de la ficción literaria y especulación filosófica.

Queda claro que la práctica historiográfica cambia de época a época, a veces incluso de generación en generación, abandonando y creando propuestas y paradigmas. Es por ello que creemos sería de utilidad saber qué noción de historia está presente en los estudios históricos de aquel momento. Aquí resulta necesario plantear algunas preguntas como: ¿qué idea se tenía de un oficio como el de la historia en aquellos años?, ¿cómo se le concebía y practicaba?, ¿qué se pensaba respecto a una posible utilidad de estudiar y escribir acerca del pasado?, ¿cuáles eran los parámetros o ejes metodológicos mediante los que se proponía practicar dicho oficio? Esbozar los puntos anteriores permitirá tener un panorama que dé cuenta de la condición de dicha práctica y ubicar en éste al personaje.

IDEAS Y AMBIENTES

La periodización que se señala para el presente trabajo tiene como márgenes la aparición de un par de obras cuyo significado y aportación en la producción historiográfica mexicana es preponderante: por un lado, el Diccionario universal de historia y de geografía, monumento de una forma de estudio del tipo erudito y con notable influencia del pensamiento ilustrado que se publicó entre los años 1853 y 1856; por otro, el México a través de

\footnotetext{
${ }^{4}$ Certeau, idem.
} 
los siglos, síntesis de la historia nacional por excelencia que fuera respaldada por la triunfante facción liberal entre 1884 y 1889 . Se trató de una época en la que se propiciaron los primeros planteamientos, prolijos y de alto nivel en torno a una actividad que pretendía encarar y resolver al menos dos preocupaciones específicas: la intención de posicionar al estudio de la historia como un ejercicio científico practicándola desde las profesiones liberales, y la utilidad que de dicho oficio se podía tener según las coyunturas político-ideológicas de ese momento.

La elite ilustrada durante la segunda parte del siglo XIX en México resultó ser un sector diferenciado que atendió un amplio campo de tareas y actividades. Una de ellas fue la proyección de una memoria nacional, la cual estuvo muy ligada a las preocupaciones, riesgos y avatares políticos del momento. Hay que advertir que, si bien el estudio y la escritura de la historia comenzaban a apuntar hacia la utilización de un método considerado científico, se llegó a ello tomando elementos de distintas disciplinas. En tal sentido, se pondrá a prueba la noción que apunta hacia una forma de escribir sobre el pasado, la cual supuso un eclecticismo donde se combinarían posicionamientos y técnicas de distintas posturas y tendencias que entonces estaban muy difundidas entre la clase política e intelectualmente activa.

La época a la que se alude permite identificar ciertos movimientos culturales e intelectuales como aquellos más representativos y que habrían tenido decisiva influencia en la forma en la cual los ilustrados de entonces hicieron el estudio y la escritura de la historia en México. Se sugiere que los de mayor incidencia en el pensamiento y obra de aquellas generaciones de hombres públicos fueron el romanticismo y el cientificismo.

Por lo que se refiere al movimiento romántico, éste se origina y propaga en Europa durante las últimas décadas del siglo XVIII y primeras del xIx y delinearía en adelante la orientación intelectual de manifestaciones artísticas y académicas, particularmente en lo filosófico y lo literario. En particular, fue entre los años de 1760 y 1830 cuando el romanticismo irrumpe como "quiebra de la conciencia europea". ${ }^{5}$

El romanticismo filosófico y literario -que llevó implícita una concepción de la historia- tuvo su gestación en lo que hoy es Alemania con

${ }^{5}$ Isaiah Berlin, Las raíces del romanticismo, 2000, 27. 
la obra de autores como Herder, Kant, Schiller, Fichte, Schelling y Hegel. Todos ellos reconocían valor y tenían simpatía por el pasado, ya que en él -pensaban- se encontrarían logros legítimos y genuinos de distintos pueblos en diferentes épocas. ${ }^{6}$ Asimismo, una constante en la postura de estos escritores es reconocerle la valía de lo sentimental, ya que, en un momento en el cual la razón parecía estar por encima de todo, el romanticismo irrumpe para mostrar que el iluminismo tiene sus límites. Así, lo que la sapiencia no puede dar al hombre en su calidad de fuerza humana finita, las experiencias y sensaciones inmediatas como el sentimiento sí pueden darlo. De tal manera que el pensamiento de dichos personajes contrapuso la religión al ámbito científico, así como las cualidades de lo nacional -entre ellas la historia-frente a la generalidad humana.

Al difundirse la escuela o movimiento romántico literario en otras latitudes por lo general tomó una forma de expresión dirigida a la exaltación de los valores y sentimientos. Una de las exaltaciones más socorridas fue la que correspondía a la representación de las experiencias nacionales. Puede decirse que en el mundo romántico prevalecen características fundamentales como el optimismo (convicción por la racionalidad y perfección); el providencialismo (conservar y perpetuar ciertas experiencias del pasado); y el tradicionalismo (apelar y exaltar a las instituciones fundamentales según elementos tradicionales). En suma, lo que a los románticos interesa es rescatar la esencia, el espíritu, lo singular que distingue a un pueblo, a una nación, a un Estado.

En México, al desatarse el movimiento independentista y aun en las décadas posteriores, el canon romántico con su respectiva atmósfera se complementará con las aspiraciones políticas, posicionamientos ideológicos y costumbres de la época. La poesía de José María Heredia (18031839) es señalada como el inicio de dicha tendencia que desplazó al neoclasicismo. Así, durante las décadas de 1830 a 1850 tal influencia arribó y se dejó sentir con fuerza en el país, en especial a través de la herencia española, a partir de la cual en el campo literario se desarrollaron postulados dirigidos a representar una mexicanidad. ${ }^{7}$

${ }^{6}$ Collingwood, Idea de la historia, 2004, 155-158.

${ }^{7}$ Pérez Salas, Costumbrismo y litografía en México, 2005, 24 y 25; 265 y ss. La autora pone énfasis en el trabajo de literatos y litógrafos en publicaciones periódicas durante la 
Centrando los argumentos en un estilo de escritura, se ha sustentado que el romanticismo literario mexicano -dentro del cual estaría parte de la escritura de la historia de la época- tuvo su auge entre los años de 1836 y 1867. Sus parámetros corresponden a la fundación de la Academia de Letrán y la restauración de la República, respondiendo a las condiciones políticas e ideológicas por las cuales atravesó la nación en dicho lapso. Así, la patria y su destino, la constitución de una identidad y conciencia nacionales, la formación de agrupaciones e institutos científicoliterarios, la edición de publicaciones periódicas y un estilo narrativo cuya aspiración era el descubrimiento de lo mexicano (lo popular, la problemática social, rescate de tradiciones, abonar por una vida institucional), son algunas de las características que se dejan ver como manifestación de ese movimiento. ${ }^{8}$

Pese a la periodización que ahora se cita, según la cual algunos estudios consideran que después de ello la tendencia romántica "como estilo histórico ha fenecido", ${ }^{9}$ la revaloración de lo mexicano dentro del romanticismo después de 1867 siguió teniendo cierta vigencia entre la clase ilustrada. ${ }^{10}$ Así lo atestiguan proyectos como el de Ignacio Manuel Altamirano (El Renacimiento, 1869) y ciertas obras de Guillermo Prieto (Romancero nacional, 1885). Con la salvedad anterior, es necesario decir que al restaurarse la República otras tendencias de pensamiento comenzarán a imponerse en la esfera pública y el ámbito académico nacional

primera mitad del siglo xIX, cuyo objetivo era conformar un "registro de tipos" en México. Así, dicho esfuerzo tanto en lo gráfico como en la descripción literaria culminó en la obra Los mexicanos pintados por símismos [1854-1855] que, a su vez, estaba inspirada en los proyectos inglés [Heads of the people, 1838-1840], francés [Les françaises peint par eux-mêmes, 1839-1842] y español [Los españoles pintados por símismos, 1842-1844].

${ }^{8}$ Martínez, "México en busca de su expresión", 2004, 722-731; Carlos Illades, Nación, sociedad y utopía en el romanticismo mexicano, 2005, 21 y 22.

${ }^{9}$ Galí, Historias del bello sexo, 2002, 14.

${ }^{10}$ Moya, La nación como organismo, 2003, 146-153; Luna, "La escritura de la historia y la tradición retórica (1834-1885)", 2004, 31-106; Matute, "Justo Sierra, el positivista romántico", 2005, 429-444. María Luna Argudín señala que en la obra México a través de los siglos convergen el liberalismo nacional, una escritura romántica y elementos del positivismo organicista. Por otro lado, tanto Álvaro Matute como Angélica Moya argumentan que la obra de Justo Sierra -ubicada en pleno Porfiriato y quien encabezara el proyecto México: su evolución social-aun guardaría resabios de un romanticismo. 
como fue el caso del positivismo, ${ }^{11}$ aunque su impacto como método para el estudio de la historia no será inmediato. ${ }^{12}$

Al propio tiempo, los avances de la ciencia y progresos tecnológicos de la época (transporte, descubrimientos, expediciones, estudios científicos) también tuvieron influencia entre quienes, practicando ciertos oficios, pugnaron por ejercerlos de forma metódica y proceder sistemático para elaborar un conocimiento con validez científica. Los ilustrados de entonces comparten el ideal clásico de la ciencia entendida como un sistema organizado de validez a partir de ciertas evidencias, la experimentación y la autocorregibilidad. Su actuar lo desarrollaron de forma positiva al dirigir su atención a una realidad efectiva y hechos establecidos para regular y ordenar el espacio público (epidemias, patologías, disfunciones sociales, problemas políticos, proyectos educativos). Puede decirse que en esa época resultó una constante apelar a la ciencia como aspiración totalitaria e integradora para encarar y resolver distintas problemáticas de la sociedad mexicana.

La propuesta que Charles Darwin (1809-1882) desarrolla en El origen de las especies (1859) sirve como ejemplo para entender el ejercicio científico de entonces, cuyo basamento era aducir a pruebas (observación, comparación, clasificación) para tratar el objeto de estudio (evolución de las especies) y llegar a una interpretación de tipo progresiva (transformismo biológico). Dicha postura también prevalece en el pensamiento social de la época al poner al progreso como idea rectora del desarrollo del orden (Comte) y el evolucionismo que ve al progreso como un impulso necesario (Spencer). En suma, en el siglo XIX se tuvo un gran optimismo en la ciencia al suponer que los problemas de la humanidad serían resueltos apelando a ella. Sin embargo, varias generaciones después nos damos cuenta que hubo una arrogancia en cuanto a concebir y utilizar tal progreso, lo cual derivó en excesos cuyas consecuencias apenas empezamos a padecer (contaminación de espacios naturales, de-

\footnotetext{
${ }^{11}$ La bibliografía sobre el tema es amplia: Leopoldo Zea, El positivismo en México, 1943-1944; Moisés González Navarro, Sociología e historia en México, 1970; Abelardo Villegas, Positivismo y porfirismo, 1972; William Raat, El positivismo durante el porfiriato (18761910), 1972; Charles Hale, La transformación del liberalismo en México a fines del siglo XIX, 1991; Elias José Palti, La invención de una legitimidad, 2005.

${ }^{12}$ Álvaro Matute, “Notas sobre la historiografía positivista mexicana”, 1991, 49-64.
} 
predación de especies animales y vegetales, sobrepoblación y hacinamiento, etcétera).

En este sentido, los hombres de ciencia quienes ejercieron alguna profesión liberal -tanto mexicanos como extranjeros radicados en el país- tras la Independencia ven la necesidad de conocer su patria, sus recursos, sus riquezas, su clima, su territorio, su flora y fauna, lo cual impulsó la elaboración de estudios que dieran cuenta de la condición nacional con el mayor detalle posible. ${ }^{13}$ Así, aspectos como la observación, el cálculo, la medición, el orden, la clasificación, comienzan a ser valorados y empleados en una incipiente práctica científica dirigida a estudios considerados estratégicos. La institucionalización del ejercicio de comunidades científicas (Sociedad Mexicana de Geografía y Estadística, 1833) y la publicación de sus investigaciones (boletines, revistas, folletos) dan testimonio de dicha vocación.

Lo anterior impactaría en los postulados y planteamientos que sobre el estudio y la escritura de la historia se empezaban a hacer en México, lo cual se percibe con cierta claridad a partir de la década de 1860. Ello debido a que la convicción de ambas tendencias (reafirmar una identidad a partir del rescate del pasado y fomentar una práctica científica cuya aspiración era la acceder a una totalidad de conocimiento organizada e inteligible) habría incidido en ello. Ambas preocupaciones irrumpieron en un ambiente político e ideológico delineado por el liberalismo militante de la clase ilustrada.

La propuesta de la escuela metódica en MÉxico

Después de identificar las tendencias de pensamiento imperantes en nuestro país durante el periodo señalado, tomamos como punto de partida el siguiente planteamiento: la configuración de un método científico para el estudio de la historia entre la elite culta mexicana tiene cierta semejanza con las condiciones desarrolladas por los historiadores europeos de la época. En particular, destacan los proyectos historiográficos alemán (L. Ranke, J. G. Droysen, E. Bernheim,) y francés (E. Lavisse, G.

${ }^{13}$ Jiménez, Las letras mexicanas en el siglo XIX, 1989, 47-56; Illades, Nación..., 2005, 27-51. 
Monod, N. D. Fustel de Coulanges, A. Rambaut) cuyos ejes (impulsar la constitución de los modernos Estados nacionales y mostrar una historia objetiva e imparcial) fueron la plataforma de la escuela metódica. ${ }^{14} \mathrm{El}$ proceso fue rematado en dichos países con la creación de una licenciatura, la elaboración de manuales metodológicos y la edición de revistas especializadas a partir de la segunda mitad del siglo XIX. ${ }^{15}$ Si bien en México la profesionalización del historiador será hasta mediar el siglo xx, la idea es advertir la constitución en aquel momento de un "ámbito" (asociaciones e institutos que agrupaban a los interesados quienes ejercían profesiones liberales) que comenzó a regular dicho oficio.

El segmento que agrupó a los hombres públicos de entonces resultó ser un activo sector diferenciado que atendió un amplio campo de tareas y actividades. Ello derivó en otra condición que es necesario señalar ahora, como fue la creación de sus propios espacios. Es decir, se trató de un momento histórico en el cual empezaron a gestarse un número importante de agrupaciones, sociedades y colectividades respecto a prácticas en los campos como el ideológico, político, literario, artístico, intelectual o académico. Resultó ser una tendencia para conformar un amplio horizonte institucional que evidenciaba la necesidad de contar con ámbitos y espacios propicios para desarrollar trabajos, actividades y quehaceres específicos. Ello fue decisivo para que la elite política e

${ }^{14}$ Dosse, La historia. Conceptos y escrituras, 2004, 29-36. El término escuela metódica fue propuesto por Gabriel Monod en el primer número de Revue Historique -de vocación republicana, espíritu liberal y herencia erudita-en 1876. A su vez, Monod estaba inspirado en lo que al respecto se hacía en Alemania (Ranke, Droysen, Treitschke, Sybel). Dosse encuentra en dicho "editorial-manifiesto" los planteamientos que regirán la historia científica como se practicó en el siglo XIX: "marcha hacia el progreso", "visión lineal de la historia", "aporte de las ciencias auxiliares", "la historia como ciencia singular" y "acceder a un conocimiento indirecto". Como veremos, tales posicionamientos y aspiraciones están presentes en las propuestas de los historiadores mexicanos de la época.

${ }^{15}$ Las primeras cátedras se imparten en la Universidad de Berlín (1810) y en La Sorbona (1812). En 1889 se publica el Lehrbuch der historischen methode und der gescchichtsphilosophie de Ernst Bernheim, el cual fue seguido por la Introduction aux études historiques de Charles Langlois y Charles Seignobos en 1898. Por lo que concierne a las publicaciones periódicas de estudios históricos, las principales propuestas se desarrollaron en lo que hoy es Alemania (Historische Zeitschrift, 1859), Italia (Rivista Storica Italiana, 1884), Inglaterra (English Historical Review, 1886) y la citada propuesta en Francia. 
intelectualmente activa de entonces se manifestara con más fuerza de forma organizada. ${ }^{16}$

Tal fiebre asociacionista era, de hecho, heterogénea y plural, con tantos grupos como intereses existían siendo la constante lograr el bien común. Ese sentido estratégico indicaba qué tareas y proyectos eran necesarios para el país, entre los que destacaba una nueva configuración ciudadana. Dicha premisa supuso, entre otras cosas, elaborar una escritura de la historia que plasmara a la nación y sirviera como referente para instruir. Por ello, la tesis anterior es útil para el presente trabajo, ya que como se mostrará desde algunas de esas organizaciones civiles (académicas, científico-literarias, periodísticas, artísticas) se plantearon y difundieron posicionamientos en pro de una historia nacional con carácter científico.

En tales condiciones es necesario hacer una mención de lo que al respecto planteaba uno de los referentes más destacados del quehacer cultural, académico, intelectual y científico desarrollado en México a mediados de aquella centuria. Tal fue el caso del Diccionario universal de historia y de geografía, monumental proyecto de carácter enciclopédico que contó con las más prominentes y destacadas figuras ilustradas del momento. Uno de los puntos que se presenta en la mencionada obra inspirada en las empresas editoriales francesa y española realizadas por aquella época, es el relativo a la historia y a la forma en la cual proponían su estudio y método.

En cuanto a la arqueología que implica reconstruir el pasado, los autores de estos volúmenes -quienes se presentaban como una "socie-

${ }^{16}$ Elias José Palti, La invención de una legitimidad, 2005, 308. Palti argumenta: “Los mexicanos entonces se reunieron en un amplio abanico de organizaciones de la más diversa especie, que van de las más reputadas e influyentes (como los clubes literarios, científicos, sociedades de prensa y profesionales, etc.) hasta otras (como las sociedades para auspiciar bailes, clubes de ajedrez, clubes de fans de las divas de la opera, etc.) organizadas en torno a cuestiones menores o para organización de actividades cotidianas y eventos sociales. Hacia los años setenta y ochenta del siglo XIX, estas sociedades congregarían, en su conjunto, miles, quizá millones de mexicanos, formando una densa malla que ligaría el tejido social desde dentro del mismo [...] Este fenómeno, que puede ser definido como el surgimiento, por primera vez en México, de una auténtica "sociedad civil" [...] tendría un profundo impacto en el pensamiento del periodo". 
dad de literatos distinguidos"-17 ya daban indicios de entender la necesidad de convertir a la historia en una disciplina con sus debidas características y condiciones. Por tanto, su propuesta iba encaminada hacia la designación y delimitación de ciertos preceptos como la consideración y el uso de fuentes para representar el pasado. De manera particular, lo que plasma una obra como la que ahora se menciona es la intención de distinguir a la historia de la práctica literaria imperante y empezar a plantear la posibilidad de un ejercicio metódico y sistemático de la investigación con un carácter propiamente histórico. Y por tratarse de una empresa que se asumía como nacionalista y estratégica para México en una época en la cual se necesitaba estabilidad, cohesión y unidad, ello se percibe en el sentido institucional que le adjudican a las fuentes y a su respectivo uso. En ese aspecto, en el Diccionario... se considera a los "documentos oficiales" como el "principal cimiento de la historia". ${ }^{18}$

Tal planteamiento pretendía dar a la máxima institución -el Estado- la posición de rector en tiempos de crisis e inestabilidad, no sólo en cuanto a regir los destinos de la nación, también para incidir en la versión que daba de sucesos ocurridos. Si la historia, como pensaban aquellos eruditos, era una de las circunstancias que definía a la nación y que compartían los mexicanos, resultaba estratégico contar con una versión legítima de ese pasado. Así, la información de carácter oficial era considerada por aquellos personajes como la base para quien se diera a la tarea de rescatar, organizar y representar ciertos episodios de épocas anteriores. Lo político y lo ideológico delinearon una de las propuestas pioneras en lo que se refiere a la escritura de la historia.

\footnotetext{
${ }^{17}$ Así lo anuncia el Diccionario universal... en la portada de la obra mencionando a Alamán, Andrade, Basoco, Diez de Bonilla, Berganzo, Conde de la Cortina y de Castro, Dávila, García Icazbalceta, Lacunza, Lafragua, Lozada y Gutiérrez, Miranda, Orozco y Berra, de la Portilla, Pesado, Pardo, Ramírez, Rayón, Roa Bárcena, Sierra, Valdovinos, Velásquez de León, Villaseñor y Noriega. Resultó común que la clase ilustrada durante buena parte del siglo XIX tuviera en la literatura su principal instrumento, el cual trataron de utilizar en pro de una estabilidad, orden y modernización que la actividad realizada en otros rubros -como el político o el económico-no habían podido lograr. Véase José Ortiz Monasterio, "La formación de la literatura nacional y la integración del estado mexicano", 2001, 419-428 y Arturo Soberón Mora, "Las armas de la Ilustración: folletos, catecismo, cuartillas y diccionarios en la construcción del México moderno", 2001, 431-444.

${ }^{18}$ Diccionario universal..., t. IV, 1854, 138.
} 
En dicha propuesta consideramos está presente un planteamiento que es próximo a uno de los postulados de Leopold von Ranke (17951886), cuyo objetivo era reconocer y trabajar fuentes que den "exposición rigurosa de los hechos" para el estudio del pasado, ${ }^{19}$ representa el inicio de la forma moderna del oficio en México. Tales hechos, como factores efectivos de sucesos históricos únicos, debían considerarse en su relación con una experiencia más amplia con el todo. Asimismo, la línea metodológica de Ranke tuvo implicaciones de tipo político-ideológico al considerar a ciertas instituciones -la Iglesia, el Estado-como imprescindibles para acceder a una civilización y modernidad. ${ }^{20} Y$ si la aspiración era un entorno moderno, civilizado y estable, el estudio del pasado debía insertarse en dicho proceso. De ahí el objetivo de desmarcar a la historia del carácter teológico, filosófico o literario que hasta entonces la definía.

Para aquellos personajes involucrados en el Diccionario..., remitirse a fuentes que identificaban como "primarias" u "originales" como las que proporcionaba la documentación oficial era una forma de ir en busca de los "hechos mismos". Del mismo modo, dicha tarea coadyuvó desde lo cultural a la conformación del estado mexicano -que atravesaba momen-

${ }^{19}$ Leopold von Ranke, Pueblos y estados en la historia moderna, 1986, 38. Guillermo Zermeño, al argumentar el proceso mediante el cual la historia consigue su estatus científico en el siglo XIX, toma como punto de partida la propuesta de Ranke en Alemania que llegaría a México a través del "krausismo español". Dicho modelo plantearía acercarse al pasado considerándolo objeto de estudio e ir al encuentro con los documentos de los archivos. Es en tal sentido que se pondera al Diccionario... como la representación de una forma moderna de concebir el estudio del pasado en México. Por su parte, Peter Novick destaca las innovaciones que aportó el historiador alemán como los métodos documentales y filológicos, un tratamiento crítico de fuentes o el desarrollo de seminarios para la formación académica, todo ello delineado por una "veneración panteista al Estado" y un "impulso romántico". Asimismo, François Dosse al estudiar la propuesta de la escuela metódica, pondera de Alemania la "capacidad de organizar una enseñanza universitaria eficaz", cuyo basamento está en la "doctrina cientificista de Ranke". Véase Zermeño, $L a$ cultura..., 2002, 77-110; Novick, Ese noble sueño, 1997, 39 y 40; Dosse, La historia en migajas, 2006, 46 y 47; Dosse, La historia. Conceptos y escrituras, 2004, 29-36.

${ }^{20}$ White, Metahistoria, 2001, 170-172. Para White, este "realismo doctrinario" propuesto por Ranke posee "implicaciones conservadoras", ya que el devenir "civilizatorio y moderno" de la humanidad sólo es posible en el contexto de instituciones como el Estado y la Iglesia. 
tos de crisis e inestabilidad- mediante la representación de datos e información que daban cuenta de una experiencia sociohistórica nacional.

Pese a lo que podría suponerse ahora respecto a que los historiadores de aquel tiempo escribían sólo con base en sus notables dotes como escritores, echando mano sólo de su prodigiosa imaginación y excelsa pluma, debe advertirse que entonces iniciaron la labor -o por lo menos hicieron intentos- para fijar ciertos parámetros que les permitieran realizar una escritura de la historia cuyo objetivo era practicarla en un ámbito delimitado. Así, es posible considerar que aquí empieza a gestarse una manera propedéutica que delineará la forma de escribir y de investigar el pasado en México en las décadas por venir. Se trató, entonces, de una empresa pionera en lo cultural y lo político con una perspectiva de grandes miras, con una vocación unitaria y totalizadora que pugnaba por realizar el estudio de una historia mexicana sustentada en el rescate y la crítica documental.

Con dicho antecedente, es a partir de la década de 1860 cuando empiezan a presentarse trabajos respecto al tema y su discusión en ese ambiente ilustrado y liberal. Los ejes de dichas propuestas versaban sobre distintos puntos: búsqueda de un ámbito y reglas propias para la historia; la historia como instrumento formativo de ciudadanos; consideración de elementos y técnicas de otras ciencias para el estudio de la historia; abonar por una historia patria o general de la nación; desarrollo de la noción que indicaría que la historia se hace con documentos.

Retomando el tema acerca de la historia patria muy vinculado a la problemática nacional del momento, ya otros destacados escritores y ensayistas habían planteado la necesidad política, ideológica y académica de elaborar una Historia general de México. Muestra de ello fue la propuesta de Manuel Larrainzar (1809-1884), "Algunas ideas sobre la historia y la manera de escribir la de México" ${ }^{21}$ Las nociones que planteó este

\footnotetext{
${ }^{21}$ Larrainzar, "Algunas ...", 1992, 185 y 186. El proyecto lo planteaba en estos términos: "Así, la Historia General de México vendría a ser el resumen, el resultado de la unión selecta, ordenada y bien distribuida de todos esos datos y noticias interesantes; mas por desgracia, todo está por hacer nada de esto existe, a excepción de algunas crónicas antiguas, bien reducidas por cierto en lo concerniente al gobierno político y al orden público, de ligeros apuntamientos y trabajos parciales relativos a varias localidades y sucesos particulares, muy interesantes sin duda, pero muy escasos y diminutos, y de algunos
} 
abogado sobre la historia correspondieron a un esfuerzo y pretensión con respaldo institucional que en el año de 1865 hiciera en la Sociedad Mexicana de Geografía y Estadística a través de la participación de sus más conspicuos miembros activos. ${ }^{22}$ También realizó el importante trabajo de arqueología intitulado Estudios sobre la historia de América, sus ruinas y sus antigüedades, comparadas con lo más notable que se conoce del otro continente, en los tiempos más remotos, y sobre el origen de sus habitantes (1875-1878).

Destacar "la utilidad, necesidad e importancia de la historia" en una nación que desde que se consuma la Independencia hasta poco después de la segunda mitad del siglo xIX se encontraba en permanente crisis, respondía a considerar la práctica de dicha actividad como instrumento para dar cohesión en torno a una conciencia patriota y nacionalista. Vamos, en el momento que Larrainzar proyecta dicha empresa, México se encuentra en una segunda aventura imperial, precisamente con la intención de encontrar e imponer un orden en un país que llevaba décadas padeciendo graves problemas y tensiones. Asimismo, cuando el chiapaneco avecindado en la capital expone dicho texto, lo "científico", lo "literario" y lo "artístico" todavía no se encuentran con una delimitación clara y precisa; de hecho, sus reflexiones se dirigen a iniciar un debate cuyo propósito era la búsqueda de un espacio para el estudio y la escritura de la historia advirtiendo la necesidad de que obtenga un carácter científico.

La ambiciosa propuesta presentada por el ilustrado apuntó a hacer una historia general, no sin antes advertir algunas cuestiones que consideraba centrales para desempeñar dicha tarea, como delimitar el objeto

rasgos ligeros y cortas indicaciones que aparecen de tarde en cuando en las historias que con pretensión de generales se han escrito. Se carece por tanto, de trabajos formados ya, adecuados para una obra de esta naturaleza en todo su desarrollo". Hay que decir que desde distintas regiones se elaboraron propuestas historiográficas que coadyuvaron a materializar dicho proyecto, como fue la del médico José Eleuterio González (1813-1888) quien desde Monterrey realizó versiones sobre la historia de Nuevo León y del entorno del bajo río Bravo a partir de 1867. Véase Edgar Iván Espinosa Martínez, José Eleuterio González, historiador, 2010.

${ }^{22}$ Ibid., pp. 142-255. Para tal propuesta el aspecto institucional era clave, ya que dichos "centros de acción" como la Sociedad Mexicana de Geografía y Estadística o la Academia Imperial de Ciencias y Literatura resultaron imprescindibles para plantear y desarrollar la magna empresa. 
de estudio, establecer las reglas, definir un método, hacer cierto tipo de escritura o aportar algún tipo de conocimiento. Pero había algo que para él era de mayor trascendencia: señalar que con el estudio del pasado se accede a un "legado de experiencia", de "verdad y justicia" a partir de lo cual los Estados y los individuos aprenderán de lo ocurrido en otras épocas. ${ }^{23}$ La historia, según Larrainzar, es para instruir, para aprender de ella, para formar individuos comprometidos con su espacio y con su tiempo. De ese planteamiento se desprende una anticipada metodología de la historia a partir de las apremiantes necesidades con las cuales el Estado nacional lidiaba. ${ }^{24}$

Pero la tarea era ardua y titánica, pues implicaba por lo menos tener una idea de qué se estaría haciendo en otras latitudes en dicha actividad en lo que entonces era un imperio. Con la convicción de encontrar una "unidad de pensamiento", se advierte una postura próxima al organicismo, en el cual las múltiples y distintas partes de un todo tienen la difícil tarea de componer un solo ente; para Larrainzar quedaba claro que México debía ser la suma de distintas realidades y condiciones, las cuales darían vida a un Estado nacional. Como se pretende mostrar, la obra y propuesta de historiadores ubicados en distintos lugares del territorio nacional respondía a tal preocupación. Con el rescate de la memoria histórica que corresponde a los distintos pueblos, entidades o regiones, así como la recuperación y organización de material ubicado en archivos civiles o eclesiásticos, se comenzaba a considerar lo necesario y útil que resultaba hacer un inventario de la información con que se contaba para elaborar una historia nacional con carácter metódico.

Existen ciertas condiciones que permiten ubicar desde un punto de vista ideológico y político a Larrainzar con la fracción conservadora de la época (formó parte de la Academia Imperial de Ciencias y Literatura, apoyó la intervención francesa y reconoció a Maximiliano), considerada tradicionalmente por la historiografía nacional como retrógrada y antipatriota. Así, al sucumbir el II Imperio y restaurarse la República, la empresa estratégica de hacer una historia general recayó en los ilustrados liberales, quedó plasmada en el México a través de los siglos. Es en estos

\footnotetext{
${ }^{23}$ Ibid., pp. 145.

${ }^{24}$ Ibid., pp. 161 y ss.
} 
términos que la citada propuesta debe ser ponderada. Así, al paso del tiempo hemos visto que la idea de dotar a México de una síntesis de su historia bajo los postulados de la escuela metódica se mantiene como una preocupación entre los historiadores mexicanos. ${ }^{25}$

Por lo anterior, es importante destacar la influencia que dicha propuesta elaborada desde lo conservador tuvo en la versión triunfal de la historia patria. En particular, la proyección de Larrainzar resultó ser de vanguardia e innovación al reconocer la singularidad étnica nacional (mestizaje); ponderar un valor ético de la historia (carácter cívico); y organizar el conocimiento sobre el pasado de forma erudita (historia integral).

El proyecto imperial fracasó y el triunfo republicano en 1867 implicó reinventar a la nación. Así, ilustrados como José María Iglesias, Guillermo Prieto y Gabino Barreda colaboraron con Juárez en ello. Por ejemplo, Barreda (1818-1881) participó en la elaboración de una nueva ley de reforma educativa la cual pugnaba por un carácter gratuito, laico y obligatorio de la enseñanza elemental y la centralización de la educación media en torno al proyecto de la Escuela Nacional Preparatoria. El principal objetivo era reivindicar al individuo considerándolo ciudadano (con derechos y obligaciones) bajo la tutela de un Estado liberal y republicano. La base de dicha propuesta se concentra en la Oración cívica. Pronunciada en Guanajuato en el mencionado año para conmemorar la Independencia justo al sucumbir la segunda aventura imperial en el país, los argumentos apuntan hacia una reconciliación nacional al amparo de la doctrina liberal. Así, Barreda se coloca entre algunos de los más destacados hombres públicos de la época (Altamirano, Prieto, Otero, Riva, Ramírez, Iglesias, Orozco y Berra) quienes, al pronunciar sus discursos cívicos septembrinos inspirados en los ideales republicanos, devinieron en cantores de la patria.

Barreda fue médico de profesión y tuvo como sus campos de acción la política y la pedagogía. La importancia que dicha Oración cívica tiene para el presente trabajo es la interpretación que su autor propone para

\footnotetext{
${ }^{25}$ De ello dan cuenta proyectos liberales como los de Justo Sierra (México: su evolución social, 1900-1902) y la propuesta de El Colegio de México (Historia general de México, 1976), así como las versiones conservadoras de Mariano Cuevas (Historia de la nación mexicana, 1940) y José Bravo Ugarte (Historia de México, 1941-1944).
} 
representar la historia de México. Ante todo, Barreda está convencido del cariz científico con el que deben estudiarse los hechos del pasado, rechazando las "influencias providenciales" y el "azar de fortuitos accidentes". El médico y pedagogo inspirado en lo que entonces se denominó física social como método de estudio positivo de los fenómenos sociales, consideró que la historia debía estar "sujeta a leyes" para "prevenir" los hechos por venir y "explicar" los que han ocurrido. ${ }^{26}$ Este método histórico permitiría apreciar de forma lineal y continua los diversos estadios de la humanidad ("teológico", "metafísico", "positivo"). Para el caso de México, con su pasado indígena, con tres siglos de vida colonial y a varias décadas de consumada la Independencia, Barreda consideró que ese momento era el inicio de un nuevo estadio. Tal estadio positivo (República Restaurada) era en el que el país debía estabilizarse a partir de un conocimiento objetivo y eficaz de sus etapas anteriores. Dicho planteamiento tiene el merito de introducir el positivismo como metodología (interpretación evolutiva de la historia) que influirá en las propuestas historiográficas de Francisco Flores (Historia de la medicina en México, 1886-1888) y Justo Sierra (México: su evolución social, 1900-1902).

La actitud preventiva de ésta historia científica concuerda con el trabajo de apostolado que llevaron a cabo personajes como Barreda. Y es que si en aquellos eruditos recayó la toma de ciertas decisiones para imponer "libertad", "orden" y "progreso" a la sociedad de su tiempo, éstas debían ser certeras y adecuadas, por lo que consideraron estratégico estudiar el pasado para no repetir los errores de las generaciones que les precedieron.

Además, existe aquí una condición relevante desde el punto de vista historiográfico, ya que aquella pléyade de ilustrados tuvo algo que-desde nuestro presente- puede considerarse una "ventaja" decisiva para interpretar mejor el pasado y reinventar a la nación: conocer el desenlace histórico de 1867. Esa "segunda independencia" -como se le llamó entonces-abrió paso al triunfo liberal y a la estabilidad que le acompañó -relativa si se quiere-, lo cual permitió a los historiadores de esa época contar con una perspectiva única para representar el pasado y proyectar el futuro.

\footnotetext{
${ }^{26}$ Gabino Barreda, Oración cívica, 1982, 448 y 449.
} 
A partir de entonces, comenzaron a circular innumerables propuestas en torno al tema nacional (historia, crónica, novela, catecismos, diccionarios, cartillas, folletería). Propiciadas por la libertad de expresión, los adelantos técnicos en la imprenta, un vivo interés de los mexicanos de entonces por la lectura y el compromiso de aquella generación romántica por dirigirse a las masas. La obra de José Tomas de Cuéllar (18301894) es muestra de ese ambiente. Escritor que habría sido asiduo participante en numerosas publicaciones y cadete en la defensa del Castillo de Chapultepec en 1847, Cuéllar todavía señalaba el vínculo entre la práctica literaria y el rescate de los hechos históricos de los pueblos y los Estados. Ambas actividades debían sustentar la tarea de sacar a la nación del marasmo en el que se encontraba.

Desde la segunda mitad del siglo XIX, Facundo -pseudónimo que adoptó-inició una prolífica actividad en el ámbito literario y periodístico. En lo que concierne a su participación en numerosos proyectos editoriales (destacan El Siglo XIX, La Linterna Mágica, El Renacimiento, La Ilustración Potosina), una constante en las ideas del personaje fue educar a los mexicanos de la época. La educación -pensaban aquellos ilustrados- podría abonar para resolver los múltiples problemas del país y coadyuvar a una unidad nacional. Al igual que otros destacados hombres públicos de entonces (Altamirano por ejemplo), Cuéllar promovió a partir de 1867 reuniones con otros escritores (Veladas literarias) para la creación y promoción de la literatura nacional.

Muestra de ello es su escrito "La literatura nacional" publicado en La Ilustración Potosina en 1869. Aquí el escritor destaca: "La literatura es no sólo el termómetro de la civilización, sino el reflejo de la historia de los pueblos. Es como la voz inmortal de las grandes catástrofes y de las transformaciones seculares, es el acento expresivo de los sacudimientos y de las revoluciones, que resuenan desde los siglos más remotos hasta la más remota posteridad" ${ }^{27}$

Al calor de los intensos debates que suscitaba la situación política nacional y animados por los preceptos ilustrados, aquella generación consideró que la promoción y práctica de la palabra escrita implicaba "una nueva era de progreso intelectual". Más que tratarse de una pro-

${ }^{27}$ Cuéllar, “La literatura ...”, 1996, 215. 
puesta estética de la época próxima al canon romántico, los escritores tomaban su oficio como instrumento con la esperanza de que ello incidiera en dotar a las naciones y los Estados de una memoria, de un pasado que la modernidad de entonces les obligaba a representar y difundir. Contar con una memoria escrita era signo de progreso y civilidad. Pero desde el punto de vista de una práctica específica, Cuéllar nos muestra que esa era una etapa en la cual la historia se encuentra todavía sujeta a los preceptos y nociones de otras disciplinas, como era el caso de la literatura. Y será precisamente dicha condición la que comienza a propiciar una reflexión y debate en torno a cuál debía ser una forma propia y adecuada para el estudio y la escritura del pasado.

Una postura muy similar es la del periodista, literato e historiador José María Vigil (1829-1909). Este ilustrado tapatío fue prolífico: desde los años de 1850 participó como fundador, director, editor y redactor en varios periódicos (El Siglo Diez y Nueve, El Monitor Republicano, Boletín de Noticias) y revistas (Revista Filosófica). También se interesa en el rescate de obras de la época colonial (Historia de las Indias, de Bartolomé de las Casas; Crónica Mexicana, de Hernando Alvarado Tezozomoc). Como historiador participó en el México a través de los siglos como autor del v tomo abordando los periodos de la Reforma, la Intervención francesa y el II Imperio.

Un par de ensayos de Vigil resultan relevantes para el trabajo. El primero de ellos apareció en 1872 en el periódico El Eco de Ambos Mundos con el título "Algunas observaciones sobre la literatura nacional". Para Vigil, la historia y la literatura son ámbitos que se complementan ya que en ambas existía un compromiso implícito: la posibilidad de traer a la memoria los diversos episodios y sucesos de las civilizaciones alrededor del mundo. México no podía quedar al margen de esa aspiración y, en tal sentido, los hombres de letras, los ilustrados e instruidos debían asumir dicha tarea como una responsabilidad histórica. El compromiso con la nación y el quehacer que desempeñaban como eruditos encontraba en ello su punto de convergencia. Así, eran los ilustrados quienes como escritores tenían la encomienda de preservar la memoria de los pueblos. Y al devenir en cantores de las "glorias nacionales", "lamentar sus desgracias presentes" y proyectar el anhelo de sus "grandes esperanzas" para su país y su gente, dicha actividad era la que consideraban 
propia del escritor. ${ }^{28}$ Mucho de ello se refleja en la escritura de la historia decimonónica.

Al igual que la idea presentada por Cuéllar, Vigil propone al ilustrado, al hombre de letras, al instruido como el único personaje capaz de recoger, representar, organizar y difundir a través de la escritura los más decisivos y trascendentes pasajes y episodios que conformarían una memoria histórica. La tarea que pensaban correspondía al historiador, la ejercían individuos con profesiones consideradas liberales como la abogacía, el periodismo o la literatura. De tal forma, y más bien dejado en lo implícito, se encontraba en los ensayistas, intelectuales y publicistas de la segunda mitad del siglo XIX una embrionaria noción del quehacer de historiador, cuyo trabajo se encontraría como parte de lo que se proyectaba como "literatura nacional". El poeta, el literato o el periodista -y el abogado como fue el caso de Larrainzar- se convertían en depositarios y divulgadores del testimonio y de los acontecimientos del devenir histórico. Era ese el lugar social desde el cual los interesados en el estudio y escritura de la historia producían su obra.

Poco tiempo después, en 1878, Vigil presentaba en el periódico $E l$ Sistema Postal el ensayo "Necesidad de estudiar la historia patria". En el proponía e impulsaba la revaloración hacía el estudio y difusión de la "sagrada" historia patria, que concibió como una "necesidad y conveniencia"..$^{29}$

La conciencia crítica y el renovado aprecio por estudiar, conocer y divulgar el pasado nacional, resultó ser una constante en las ideas plasmadas por los más descollantes escritores y polemistas de ese tiempo. Aquí se ha hecho referencia a ellos como ilustrados o eruditos, resueltos a crear y promover un tipo de conocimiento respecto a la recuperación del pasado, pero también a elaborarlo bajo una forma sistemática. Dicho conocimiento se encontraba enmarcado en lo que fue el vasto campo conformado por el binomio científico-literario. De esa manera periódicos, libros, revistas, panfletos, discursos, entre otros medios, fueron los instrumentos de los que se valieron aquellos hombres de letras para presentar y difundir sus ideas y preceptos. Ideas que se encaminaban, entre

\footnotetext{
${ }^{28}$ Vigil, “Algunas...", 1996, 262.

${ }^{29}$ Vigil, “Necesidad ...", 1992, 265-278.
} 
otras cosas, al rescate de las antigüedades y del pasado nacional "olvidado" e "ignorado", según Vigil. La historia, considerada por este liberal como parte de un ejercicio científico-literario, era la idónea para acometer esa empresa que tenía un profundo sentido práctico a partir de dos vetas: que el estudio del pasado formara parte de una instrucción moderna y organizada, y al propio tiempo sirviera para posicionar a México como una nación civilizada y progresista. ${ }^{30}$

Si bien en los casos de Cuéllar y Vigil se revalora el pasado nacional desde la literatura, poco a poco dichos debates empiezan a tratar de desmarcar a los estudios de historia de dicho ámbito, aunque quienes lo promueven entienden que para representar el pasado necesitan técnicas y elementos de otras disciplinas.

Uno de aquellos destacados ilustrados que escribiera acerca del Estudio de la historia fue José María Iglesias (1823-1891), quien señaló que el trabajo de investigación para representar el pasado no dependía sólo de detectar los acontecimientos y vicisitudes, sino de ubicarlas en tiempo y en espacio. Por ello, el también periodista, abogado y político indicaba que de entre las varias disciplinas que la historia debía echar mano para lograr ese "carácter verdaderamente científico", estarían la cronología, la geografía, la antropología, la geología, la sociología, las cuales tendrían una "importancia suprema". ${ }^{31}$

Como sucedió con los personajes aquí aludidos, Iglesias vivió las convulsiones y crisis de México en aquella centuria. Particular impacto causaron en él las invasiones de los ejércitos estadounidense y francés. Lo anterior quedó plasmado en dos proyectos en los que participó: Apuntes para la historia de la guerra entre México y los Estados Unidos, trabajo colectivo publicado justo en el año que culminó dicho conflicto, y las Revistas históricas sobre la intervención francesa en México, cuyos 49 números los elaboró durante el tiempo que duró la estadía de las tropas extran-

\footnotetext{
${ }^{30} \mathrm{Ibid} ., \mathrm{pp} .271$.

${ }^{31}$ Iglesias, El estudio de la historia, 2003, 80 y 81 . A decir de Antonia Pi-Suñer -quien coordinó al grupo que encontrara, estudiara y trasncribiera el manuscrito- estas premisas Iglesias las vertía durante los últimos años de su vida, en la década de 1880. Y aunque permanecerán inéditas hasta el año 2003 -momento en que se publican- en este trabajo se le considera un ejercicio contemporáneo al de los historiadores aludidos por lo cual se incluye.
} 
jeras (1862-1866). Asimismo, existe otro dato de relevancia desde un punto de vista político e ideológico: fue uno de los que acompañó a Juárez como parte del gobierno republicano (fue Secretario de Justicia, Fomento e Instrucción Pública) en su resistencia a la invasión gala y al II Imperio.

Al igual que los autores del Diccionario... varios años antes, Iglesias pugnó por un ejercicio riguroso y metódico en pro de una historia científica. Como otros tantos ilustrados de aquel tiempo, Iglesias se muestra como un hombre convencido en el futuro quien no tiene dudas sobre el porvenir que a México le espera. El progreso y perfeccionamiento que en las distintas esferas y rubros se percibía entonces, también incidirían en la forma de abordar la historia. Por ello algunos estudios e investigaciones sobre aquellos autores, sus obras y su respectivo contexto, han detectado planteamientos semejantes y próximos a los de la sociología, rama del conocimiento humano que se manifestaba entonces con fuerza. ${ }^{32}$

Dicha aspiración al "orden" y al "progreso" era reflejo de la máxima positivista ya presente en el ámbito político, científico y académico, y que pronto dejaría sentir su influjo en el estudio de la historia. Así, aspectos de otras ciencias que el personaje consideraba relevantes eran los relacionados con la cronología y la geografía en la forma de estudiar y de escribir la historia. A ambas ramas del conocimiento, Iglesias les daba una gran importancia como "ciencias auxiliares de la historia". ${ }^{33}$

Por ejemplo, "medir" o "sopesar" los progresos de un pueblo, de una sociedad o de un Estado a través del tiempo de forma comparativa debía ser una de las aportaciones para estudiar el pasado de forma íntegra y total. De tal manera que ubicar en un espacio y lugar específicos los sucesos y vicisitudes ocurridos en otro tiempo era algo crucial para acercarse a ello, descifrarlo y comprenderlo. También resultaba útil-entre otras cosas- para hacer el inventario de la nación y conocer así los recursos naturales con los que se contaba para localizarlos y explotarlos.

\footnotetext{
${ }^{32}$ Ortiz Monasterio señala el "lenguaje sociológico" y la "literatura de orientación social" presentes en la escritura de la historia de la época, aludiendo a los elementos de otras disciplinas que eran tomados y adaptados por quienes entonces realizaban estudios sobre el pasado. Véase Ortiz, México..., 2004, 124-187.

${ }^{33}$ Iglesias, El estudio..., 2003, 151.
} 
Por lo tanto, la historia para Iglesias por sí sola se volvía incapaz de abordar al pasado en toda su complejidad. ${ }^{34}$

Apelar a la "observación", la experimentación", la "generalidad", la "sistematización", la "clasificación", la "perfectibilidad" resulta en Iglesias una constante como heredero de la racionalidad ilustrada, imbuido en el ambiente liberal y dispuesto a encontrar un lugar para la historia en el concierto de las ciencias. ${ }^{35}$ Vale agregar que la postura proyectada por el abogado respecto a los estudios de historia es muy próxima a lo que años más tarde plantearán Langlois y Seignobos para afianzar un proceder metódico que superara la retórica literaria y especulación filosófica ${ }^{36}$ Ello nos permite advertir que en México, durante aquella época, ya se delineaban posicionamientos propios sobre la forma de desarrollar los estudios de historia. También es necesario advertir que dichas posturas no eran simplemente tomadas de aquellas propuestas realizadas por sus pares del otro lado del Atlántico, sino que, inspirados en ellas, los

\footnotetext{
${ }^{34}$ Ibid., p. 155.

${ }^{35}$ Iglesias, El estudio..., 2003, 140 y 141. Iglesias consideró: “Por medio de la observación y de la experimentación, fuentes seguras de todo conocimiento inductivo, se logra el descubrimiento de leyes, encadenadas luego entre sí. Las primeras son fáciles y sencillas; las siguientes ofrecen ya mayores dificultades; las últimas presentan complicaciones tan serias, que todavía aparecen bien lejanas las épocas en que sean descubiertas, comprobadas y admitidas. Mucho se ha adelantado ya, sin embrago, en la época actual, con sólo el reconocimiento, difundido en todo espíritu ilustrado, por una parte de la existencia de las leyes mencionadas, y por otra del método necesario para descubrirlas. Procediendo de generalización en generalización, hasta llegar a las más avanzadas, se recorrerá el camino al través del cual avanzarán nuestros póstumos a una perfectibilidad para nosotros desconocida".

${ }^{36}$ Fue el caso de la ya mencionada Introduction aux études historiques publicada en 1898. Se trató de un manual redactado por ambos historiadores dirigido a los estudiantes de historia de La Sorbona, en el cual se definían tanto el método como los propósitos de una escuela metódica en dicha disciplina. Llama la atención como estos autores abogaban respecto a un cúmulo de conocimientos que debían ser tomados de otras disciplinas para investigar sucesos del pasado, siempre y cuando pudieran ser útiles según el objeto de estudio y el momento histórico en el cual se ubique. Así, y ya asentada la propuesta organizada y sistemática en el estudio de la historia, resultaban necesarios conocimientos de literatura, filología, arqueología, numismática o heráldica para que quien investiga épocas o procesos del pasado tenga instrumentos para descubrir, comprender y examinar críticamente aquellas evidencias que encuentra. Existe una versión en español de 1972 por Editorial La Pléyade de Buenos Aires con la traducción de Domingo Vaca.
} 
ilustrados mexicanos creaban las propias según las condiciones sociales y políticas en las que se encontraban.

La preocupación por elaborar una historia patria con un marcado carácter liberal se hizo presente en un momento de cierta estabilidad política. Una noción que se sumó a ese contingente de voces fue la de Vicente Riva Palacio (1832-1896). Su ámbito de acción fue variado y abarcó distintos géneros: ejerció el periodismo (La Orquesta, El Correo del Comercio), fue novelista (Calvario y Tabor, Martín Garatuza, Monja y casada), dramaturgo (El abrazo de Acatempan, Odio heredado), poeta (El Escorial, Al Viento), cuentista (Las honras de Carlos V, La leyenda de un santo) e historiador (El libro rojo, 1520-1867). Obtuvo el grado de general con el cual combatió la intervención del ejército francés al mando de guerrillas en Michoacán y el Estado de México. Nos encontramos ante el prototipo del héroe romántico quien luchó tanto con la pluma como con la espada por la libertad de la nación. La culminación de este actuar es el México a través de los siglos.

En esta obra que dirigió, Cero -pseudónimo de Riva-señala el compromiso presente en aquellos ilustrados quienes, devenidos en historiadores, estaban convencidos y resueltos a hacer una historia "severa", "imparcial", "justa". Se asemeja, como vemos, a un tribunal que ajusticia a ciertos personajes y define el sentido de algunos episodios, pero siempre "con la luz que les es propia" ${ }^{37}$ Justo esa severa imparcialidad debía darse haciendo una lectura adecuada de los sucesos ocurridos, reconstruyendo y representando las condiciones en las cuales se dieron. Aspiración que, con otras circunstancias y distintas condiciones, quienes ahora investigan y escriben acerca de lo sucedido en otras épocas, todavía consideran los historiadores profesionales.

Ligado a lo anterior hay una situación que es necesario advertir. Es el caso de la experiencia que como generación tuvieron los personajes aludidos, pues los sucesos de la historia nacional ocurridos durante buena parte de aquella centuria incidieron en su actuar y en su pensamiento. Siendo tan caóticos y desafortunados dichos episodios para la entonces joven nación, algunos de los más destacados hombres públicos de la época le apostaban a un futuro prometedor y lleno de posibilida-

\footnotetext{
${ }^{37}$ Riva Palacio, México a través de los siglos, t. II, 1889, pp. XII.
} 
des. Quizá por ello dejan ver en sus planteamientos la idea de progreso, de dirigirse hacia adelante para dejar atrás los lamentables y desastrosos episodios que les había legado el pasado. Su fe y esperanza estuvo puesta en el porvenir luego de superar las crisis. Y para evitar repetir tales experiencias creyeron necesario conocerlas para no volver a repetirlas. Era de esa forma que la historia resultaba útil y necesaria.

Riva ocupa una posición de privilegio en la historiografía mexicana del siglo xIX. Portador de una herencia "propiamente ilustre", este historiador fue de esos afortunados al tener una buena posición social en el México que les tocó vivir. ${ }^{38}$ Aspectos como pertenecer a una familia que contaba con ciertos recursos económicos y formar parte de una elite política, económica y cultural, así como haber tenido la posibilidad de educarse en profesiones liberales, le permitió acceder a esferas de acción como la intelectual y la política. Esta última, en la misma cúpula del poder donde Riva ocupó carteras importantes como la de Ministro de Fomento entre los años que corren de 1876 a $1879 .{ }^{39}$

Según lo señala Ortiz Monasterio, lo que acabó por ser México a través de los siglos, derivó de un encargo del gobierno mexicano en 1881 -sien-

\footnotetext{
${ }^{38}$ Ortiz, México..., 2004, 67-73. José Ortiz-Monasterio destaca el ambiente familiar y la ubicación social de Riva: nieto de uno de los "padres de la patria" -Vicente Guerrero-y parte de la "nueva aristocracia" cuyo "talento" y "prestigio social" les permitió sobresalir.

${ }^{39}$ La publicación de los Anales del Ministerio de Fomento de la República Mexicana representó un intento estratégico desde un punto de vista político por ser un cúmulo de información sobre situaciones, características, condiciones y problemáticas del país. En él se presentaban estudios que abarcaban diferentes aspectos de la realidad nacional en ese momento; investigaciones, trabajos de campo y viajes de reconocimiento o exploración que tenían que ver con lo geográfico, histórico, estadístico, la salud e higiene, condiciones materiales de caminos, etcétera, eran enviados desde distintas latitudes del país. La intención era hacer una miscelánea de los trabajos realizados por médicos, ingenieros, geólogos, historiadores, militares, geógrafos, entre otros especialistas, para tener conocimiento acerca de cómo se encontraba la nación en diversos rubros. Así se pretendía tener una noción sobre cuáles carencias y retos existían, qué posibilidades había para atenderlas, con qué tipo de recursos naturales se contaba, qué habría que hacer para extraerlos y explotarlos. Se trató de uno de los más anticipados diagnósticos -resultado de una sistemática labor empírica- para tener un referente de la "realidad nacional". Lo realizado por José Eleuterio González en campos como el de la medicina, la historia y la estadística, teniendo como objeto de estudio las condiciones de Monterrey y la entidad, se mantiene en estrecha relación con ese tipo de "obras tan instructivas" y de "interés científico".
} 
do presidente Manuel González y recibiendo la invitación por parte de Jerónimo Treviño-para realizar la historia sobre la Guerra de Intervención y el Imperio. ${ }^{40}$ Los resultados del proyecto comenzaron a presentarse hacia 1884, en pleno liberalismo porfirista y en una época en la cual -si bien con sus salvedades- se superaban las condiciones de inestabilidad que por décadas habían acechado al país. En todo caso, la puesta en marcha de un proyecto tan ambicioso como el de escribir una historia general auspiciada por el Estado mexicano cuyo perfil era liberal, es muestra de un esfuerzo político, ideológico e intelectual sin precedentes de un gobierno nacional por hacer manifiesto su carácter legítimo y acceder a una autonomía plena.

Por lo que corresponde a su posición frente a la escritura de la historia, las cinco grandes etapas históricas rescatadas y representadas en México... (mundo indígena, Virreinato, Independencia, vida independiente y Reforma) son ejemplo del más ambicioso proyecto intelectual dentro del liberalismo porfirista por integrar al Estado nacional mexicano. También manifiesta la estabilidad que, en algún grado, logró el régimen de Díaz a lo largo de su prolongado espacio temporal. Asimismo, implicó un arduo trabajo por recopilar información de todo tipo, la cual se encontraba en distintos lugares, desde documentación ubicada en varios archivos del extranjero hasta obras historiográficas, crónicas, apuntes históricos y folletería acerca del pasado regional elaborada en varios puntos de la república.

Otro personaje relevante de esa época también interesado en la historia fue Guillermo Prieto (1818-1897). Fidel -como firmó algunos de sus trabajos-colaboró en los Apuntes para la historia de la guerra entre México y Estados Unidos, publicados en primera instancia en el periódico El Siglo XIX en diecisiete entregas entre septiembre de 1848 y mayo de 1849. Impulsor y figura del romanticismo en nuestro país, también promovió y participó en numerosos proyectos editoriales como revistas (El Museo Mexicano, 1843-1845; Revista Cientifica y Literaria, 1845-1846) y periódicos (El Ateneo Mexicano, Semanario Ilustrado, El Monitor Republicano, El Universal) donde manifestó su apego a las tesis cientificistas y su adhesión al credo liberal. Asimismo, como escritor romántico realizó trabajos donde

${ }^{40}$ Ortiz, México ..., 2004, 189. 
valora la experiencia de lo cotidiano (Viajes de orden suprema, 1857; Musa callejera, 1883; Romancero nacional, 1885) cuyo objetivo era mexicanizar la literatura. Al igual que los mencionados Barreda e Iglesias, Prieto fue de los civiles destacados que acompañaron a Juárez en el proyecto de restauración republicana en 1867.

Prieto se dio a la tarea de elaborar una representación del pasado nacional que plasmó en obras como Lecciones elementales de economía política (1876), Compendio de historia Universal (1888) y las Lecciones de historia patria (1886). Como tantos libros de historia nacional que circularon entonces, dichas Lecciones de historia... tuvieron el respaldo institucional al ser considerado texto oficial en lugares como el Colegio Militar y la Escuela Nacional Preparatoria.

Para aquellas generaciones, la historia como parte de las ciencias modernas debía ser instrumento efectivo para el proyecto liberal de enseñanza en la hora republicana y en el porfiriato después. Se sumó esta historia a las versiones liberales que aparecieron y se difundieron durante el Porfiriato, cuyo objetivo era "exaltar el sentimiento de amor a la patria" y difundir los "buenos principios liberales, fundados en la observación y en la ciencia" ${ }^{41}$ Como se advierte, Prieto con su propuesta historiográfica se inserta en la línea metódica para el estudio del pasado inaugurada en México por el Diccionario universal... sistematizada por Larrainzal y profundizada por Iglesias. Además, para Fidel conocer de manera científica los procesos de otras épocas (etapas, instituciones, personajes) debe ir de la mano con su enseñanza para las nuevas generaciones. Dicho sentido "intencional" de enseñar la historia patria a los mexicanos de entonces -en particular a los jóvenes que en ese momento reciben algún tipo de educación-, todavía posee sus rasgos de romanticismo (interés por el pasado y exaltación de un nacionalismo) y de un liberalismo que apela al orden y progreso (doctrina cientificista).

Hasta aquí es importante destacar similitudes y coincidencias de las propuestas de los historiadores mexicanos con los postulados científicos y metodológicos (uso de documentos como fuente primaria, tomar elementos de otras disciplinas, reconocer la distancia temporal respecto al objeto de estudio) que entonces afianzan la práctica profesional del ofi-

\footnotetext{
${ }^{41}$ Prieto, Obras..., t. xxvIII, 1999, 448 y 449.
} 
cio en Europa. Sin embargo, llama la atención en este punto la arrogancia de prominentes historiadores quienes, en su afán de desmarcarse de lo que consideran "construcciones abstractas" de los "no profesionales", vieron con desdén dichas aportaciones. ${ }^{42}$ Pese a su condición "no profesional", encontramos que los ilustrados mexicanos referidos manifestaron en sus reflexiones una idea científica, metódica y sistemática -que hasta cierto punto resultó innovadora y vanguardista- respecto al estudio de la historia.

A más de un siglo de distancia, una lectura que puede sintetizar ese proceso de posicionamiento ideológico, preocupación política y quehacer intelectual plasmado en la escritura de la historia, es la que al respecto hace y propone Antonia Pi-Suñer: la promoción y afirmación del nacionalismo impactó a la escritura de la historia en su tarea de elaborar un discurso integrador. ${ }^{43}$

Es en este sentido que puede distinguirse la existencia de una "conciencia" en torno a la actividad de escribir y a su utilidad según la coyuntura del momento, como lo argumenta Jorge Ruedas de la Serna al referirse a la misión del escritor, ya que:

En su conjunto, sin embargo, prueba que la actividad literaria del siglo pasado estuvo acompañada de una amplia reflexión, o podíamos decir "autorreflexión", de quienes ejercieron el oficio de escritor y contribuyeron a darle una especial dimensión entre las actividades humanas, mayormente

${ }^{42}$ Langlois y Seignobos, Introducción a los estudios históricos, 1972, 7. Los historiadores franceses señalaban de manera tajante: "No hemos querido enriquecer con un número de bibliografía tan abundante de la que se acostumbra a llamar 'Filosofía de la historia'. Pensadores que en su mayor parte no son historiadores de profesión, han hecho de la historia objeto de sus reflexiones, han buscado en ella las 'semejanzas' y las 'leyes', y algunos ha creído descubrir 'las leyes que han precedido el desenvolvimiento de la humanidad' y 'construir' así la 'historia como ciencia positiva'. Estas bastas construcciones abstractas inspiran, no solamente al público, una desconfianza invencible a priori [...] Con razón o sin ella (sin ella, indudablemente) la Filosofía de la historia, no habiendo sido cultivada solamente por personas bien informadas, prudentes, de inteligencia fuerte y sana, está desacreditada".

${ }^{43}$ Pi-Suñer, "La generación de Vicente Riva Palacio y el quehacer historiográfico", 1996, 89; "Introducción", Historiografía Mexicana, vol. IV, En busca de un discurso integrador de la nación, 1848-1884, pp. 9-30. 
resaltando su utilidad y su importancia para mejorar a la sociedad, depurar sus costumbres, robustecer la moral pública, revalorar nuestro patrimonio geográfico y cultural, afirmar nuestra identidad y, con todo ello, fortalecer la conciencia nacional. ${ }^{44}$

Puesto en la discusión el señalamiento anterior, es posible advertir que en el periodo señalado del siglo XIX, la elaboración de la historia se distinguió por un cariz romántico, vocación científica, una inspiración nacionalista y una elaboración del tipo erudito. Ello tendría entre sus principales metas proponer la formación de un tipo de ciudadano íntegro, así como contribuir a la construcción de un estado mexicano fuerte, estable y moderno a través de un discurso historiográfico. Para ambos objetivos aquellos historiadores consideraban menester recuperar y difundir el pasado como parte de la experiencia nacional.

\section{CONSIDERACIONES FINALES}

Como sabemos, fue al mediar el siglo xx cuando se conformó un ámbito profesional en el oficio de historiar con proyectos desarrollados en instituciones públicas (El Colegio de México, 1940; Escuela Nacional de Antropología e Historia, 1942; Universidad Nacional Autónoma de México, 1945). Sin embargo, encontramos evidencias de que existe debate y reflexión sobre una nueva forma de apropiarse del pasado cuya propuesta anticipó por casi una centuria a dicha profesionalización. De modo que se logró detectar en aquellos posicionamientos una línea metódica para el estudio y la escritura de la historia, lo que representa el inicio de una práctica moderna amparada en el influjo de los avances científicos y en los postulados del romanticismo en un ambiente donde privaron las ideas liberales.

A diferencia de lo ocurrido en lugares como Francia, Alemania, Inglaterra o Estados Unidos, donde entonces se empezó a delinear para la historia un campo propio entre las disciplinas científicas -lo que se manifestó en la fijación de reglas para desempeñar el oficio, su regulación a

${ }^{44}$ Ruedas de la Serna, La misión del escritor, 1996, 7 y 8 (Presentación). 
través de escuelas y facultades y la aparición de publicaciones periódicas donde se difundían los conocimientos obtenidos-, en México ese ejercicio fue llevado a cabo desde la actividad que desarrollaron los profesionistas en un ambiente liberal. Pero incluso en aquellos esfuerzos encaminados a una incipiente profesionalización de la historia en los países mencionados, su fundamento metodológico todavía estaba amparado en el modelo cognitivo de las ciencias naturales, aunque ya dejaban ver cierto ejercicio de crítica documental. Se trató de una época donde la tarea primordial fue -en palabras de Novick-la "entronización de la objetividad". Tal posicionamiento metodológico tuvo en la propuesta de Langlois y Seignobos a fines del siglo XIX su forma más acabada. En suma, se fomentó -según Dosse-una historia próxima al tipo ideográfico, de carácter erudito y por lo general con el respaldo -y el condicionamiento- del Estado.

Por lo que correspondió a las posturas de los ilustrados mexicanos referidos en el primer capítulo, la dependencia que en esa actividad tuvieron respecto a la abogacía, la literatura o el periodismo, se encontró un primer intento sistemático por superar la especulación filosófica y la ficción literaria, así como la toma de ciertos elementos de otros campos de estudio para la indagación y la representación del pasado. Y fue este último punto lo que permitió a los historiadores acercarse a otras disciplinas (estadística, geografía, cronología, heráldica, numismática) para articular un método científico de estudio. Fue Manuel Larrainzar quien logró plantear tal proyecto a mediados de la década de 1860 -durante el II Imperio-, aunque habrán de pasar casi veinte años para que el equipo dirigido por Vicente Riva Palacio lo desarrolle -en pleno liberalismo porfirista-.

Aquella generación de profesionistas liberales se encontró entre dos posicionamientos que delinearon la manera de esgrimir sus argumentos: desde un punto de vista escriturístico, estuvieron ubicados en un romanticismo dirigido al rescate y exaltación de lo nacional, por lo que acudieron a los postulados del romanticismo; $y$ en lo que se refiere a una metodología -más bien implícita e inspirados en el cientificismo de la época-, se encontraron aspectos como la "validez" del conocimiento histórico, lo que se saldó con la utilización de documentos escritos, en particular los oficiales. Con dicha fuente como elemento principal e in- 
discutible y una escritura del tipo romántico, se presentó una visión por lo general evolutiva y lineal de los procesos históricos.

Se trató de un momento en el cual comenzaba a desarrollarse y consagrarse un nuevo tipo de lenguaje -y de escritura por supuesto- acerca del pasado, en lugares específicos de producción y con comunidades autorreguladas y entrelazadas entre sí en algún grado. Es decir, se empezó a gestar en México una historiografía de cariz moderno e inspiración republicana.

Lo anterior tuvo como finalidad una constitución de ciertos referentes históricos mediante los cuales fuera posible consumar una doble aspiración: por un lado, elaborar un estudio de la historia con carácter científico; por otro, rescatar la individualidad histórica de la nación mexicana. En este último aspecto, la historiografía forma parte de una cultura nacional que se deseaba reconstruir y difundir. Así, en la labor de los ilustrados mencionados estamos ante una propuesta de representación nacional elaborada "desde arriba", amparada en la mayoría de los casos por el Estado que a partir de 1867 da señales de una relativa estabilidad. Bajo estas circunstancias, el credo liberal fue el que se impuso en una versión de la historia hecha y difundida por los vencedores.

Desde un punto de vista institucional, y pese a la citada dependencia respecto a otras ciencias, ya aquellas generaciones de eruditos organizaron sus propios espacios en los cuales se propiciaba la discusión, el debate y la reflexión sobre el tema de la historia (asociaciones literarias, sociedades científicas, institutos, colegios, revistas, periódicos). Asimismo, estamos ante una propuesta de historia metódica mexicana que se gesta al calor de los procesos políticos y sociales que experimentó el país en aquella centuria.

La elite ilustrada también es muestra del ascenso de una nueva clase social a lo largo de dicha centuria, la cual ya no se vinculaba con el rancio abolengo de familias novohispanas, ni con ciertos apellidos considerados de alcurnia. Se trató, más bien, de personajes cuyo ascenso social fue resultado del tipo de actividades que desempeñaron (abogados, médicos, militares, literatos, periodistas, profesores), ligadas siempre a las problemáticas cotidianas de sus respectivos entornos.

Por otra parte, la efervescencia nacionalista y el sentido épico que le acompañó ("patria", "libertad", "pueblo", "honor", "gloria") presentes 
en las propuestas de aquellos historiadores debe entenderse a la luz de ese presente que les tocó vivir, y en algunos casos, combatir y derrotar. Así, para nosotros, ubicados en otra época y con otras condiciones, el Estado mexicano-lejos de ser perfecto-es algo dado cuyas instituciones (políticas, educativas, judiciales, de seguridad social, electorales, etcétera) regulan nuestra vida diaria. En contraste, para aquellas generaciones la existencia del Estado nacional implicó una ardua lucha que se libró no sólo con las armas, también se llevó a cabo con la fuerza de las ideas. Es en este punto donde el influjo del romanticismo en las propuestas historiográficas abordadas se hace presente; así, ir al encuentro con el "origen", cantarle al terruño, exaltar a los héroes, y sobre todo, dirigirse a las masas, fueron condiciones que contribuyeron a la práctica metódica de la historia en México.

La práctica profesional del oficio en nuestro país con casi siete décadas logra su fin en sí misma al construir conocimiento sobre el pasado, por lo cual casi todo es análisis. En contraste, para aquellas generaciones la historia no fue un fin sino un medio indispensable y efectivo para la tarea estratégica de integración nacional. No se trata de hacer una comparación entre unos y otros, sino de valorar en su justa dimensión -“con la luz que les es propia", como señala el epígrafe de Riva-las aportaciones de cada época.

BibLIOGRAFÍA CITADA

BERLIN, Isaiah, Las raices del romanticismo, Madrid, Santillana Ediciones, 2000.

BRADING, David, Mito y profecía en la historia de México, trad. Tomás Segovia, México, Fondo de Cultura Económica (Sección de Obras de Historia), 2004 (edición original en inglés 1984).

CERTEAU, Michel de, La escritura de la historia, trad. Jorge López Moctezuma, México, Universidad Iberoamericana/Instituto Tecnológico y de Estudios Superiores de Occidente, 2006 (edición original en francés 1975).

CuÉLLAR, José Tomás de, "La literatura mexicana”, La misión del escritor. Ensayos mexicanos del siglo XIX, Jorge Ruedas de la Serna organización 
y presentación, México, Universidad Nacional Autónoma de México-Coordinación de Humanidades (Ida y regreso al siglo XIX), 1996.

Diccionario Universal de Historia y de Geografía, obra dada a luz en España por una sociedad de literatos distinguidos, refundida y aumentada considerablemente para su publicación en México con noticias históricas, geográficas, estadísticas y biográficas sobre las Américas en general y especialmente sobre la República mexicana, México, Tip. de Rafael y Vilá/Librería de Andrade y Escalante, tt. I y IV, 1853-1856.

Dosse, François, La historia en migajas. De Annales a la "nueva historia", trad. Francesc Morató i Pastor, México, Universidad Iberoamericana-Departamento de Historia (El oficio de la historia), 2006 (edición original en francés 1987).

, La historia. Conceptos y escrituras, trad. Horacio Pons, Buenos Aires, Nueva Visión (Colección Claves), 2004 (edición original en francés 2000).

Galí Boadella, Montserrat, Historias del bello sexo. La introducción del romanticismo en México, México, Universidad Nacional Autónoma de México- Instituto de Investigaciones Estéticas (Estudios y fuentes del arte en México, 72), 2002.

IgLESIAS, José María, El estudio de la historia, transcripción, investigación y edición de Antonia Pi-Suñer Llorens, , coord., María Hernández, Juan Macías, Samantha Álvarez, México, Universidad Nacional Autónoma de México/Fondo de Cultura Económica (Sección de Obras de Historia), 2003.

Illades Aguiar, Carlos, Nación, sociedad y utopía en el romanticismo mexicano, México, Consejo Nacional para la Cultura y las Artes (Sello Bermejo), 2005.

JimÉNEz RuEDA, Julio, Letras mexicanas en el siglo XIX, México, Fondo de Cultura Económica (Colección Popular 413), 1989.

LANGloIs, C. V. y C. SeIGNOBos, Introducción a los estudios históricos, trad., Domingo Vaca, Buenos Aires, Editorial La Pléyade, 1972 (edición original en francés 1898).

LARRAINZAR, Manuel, "Algunas ideas sobre la historia y manera de escribir la de México, especialmente la contemporánea, desde la declaración de Independencia en 1821, hasta nuestros días", Polémicas y ensayos mexicanos en torno a la historia, Juan A. Ortega y Medina, México, 
Universidad Nacional Autónoma de México-Instituto de Investigaciones Históricas (Serie Documental 8), 1992, (primera edición 1970).

LuNA ARGUDín, María, "La escritura de la historia y la tradición retórica (1834-1885)", La tradición retórica en la poética y en la historia, Jorge Ruedas de la Serna, María Luna Argudín y Leticia Algaba, México, Universidad Autónoma Metropolitana-Azcapotzalco/Consejo Nacional de Ciencia y Tecnología (Cuadernos a debate 3), 2004.

Martínez, José Luis, "México en busca de su expresión", Historia general de México (Versión 2000), México, El Colegio de México (Centro de Estudios Históricos), 5a. reimpresión, 2004.

MAтUTE, Álvaro, "Notas sobre la historiografía positivista mexicana", Secuencia. Revista de Historia y Ciencias Sociales, México, Instituto Mora, núm. 21, septiembre-diciembre 1991, 49-64.

-, "Justo Sierra, el positivista romántico", La república de las letras. Asomos a la cultura escrita del México decimonónico, Belem Clark de Lara y Elisa Speckman Guerra, eds., México, Universidad Nacional Autónoma de México- Coordinación de Humanidades (ida y regreso al siglo XIX), v. 3, 2005.

Novick, Peter, Ese noble sueño. La objetividad y la historia profesional norteamericana, trad. Gertrudis Payás e Isabel Vericat, México, Instituto Mora, t. I, 1997 (edición original en inglés 1988).

ORTIZ MONASTERIO, José, “La formación de la literatura nacional y la integración del estado mexicano", Empresa y cultura en tinta y papel (18001860), Laura Suárez de la Torre, coord. gral., Miguel Ángel Castro, ed., México, Instituto Mora/Universidad Nacional Autónoma de México, 2001.

, México eternamente. Vicente Riva Palacio ante la escritura de la historia, México, Instituto Mora/Fondo de Cultura Económica (Sección de Obras de Historia), 2004.

PANI, Erika, Para mexicanizar el Segundo Imperio. El imaginario político de los imperialistas, México, El Colegio de México/Instituto Mora, 2001.

Pérez Salas, María Esther, Costumbrismo y litografía en México: un nuevo modo de ver, México, Universidad Nacional Autónoma de MéxicoInstituto de Investigaciones Estéticas (Monografías de Arte 29), 2005. 
PI-SuÑER LloRENS, Antonia, “La generación de Vicente Riva Palacio y el quehacer historiográfico", Secuencia. Revista de Historia y Ciencias Sociales, México, Instituto Mora, núm. 35, mayo-agosto 1996, 83-108.

, "Introducción", En busca de un discurso integrador de la nación, 1848-1884, (Historiografía Mexicana vol. Iv, Juan A. Ortega y Medina y Rosa Camelo, coord. gral.), México, Universidad Nacional Autónoma de México-Instituto de Investigaciones Históricas, 1996.

RANKE, Leopold von, Pueblos y estados en la historia moderna, trad. Wenceslao Roces, México, Fondo de Cultura Económica (Sección de Obras de Historia), 1986.

Riva Palacio, Vicente, dir., México a través de los siglos. Historia general y completa del desenvolvimiento social, político, religioso, militar, artístico, científico y literario de México desde la antigüedad más remota hasta la época actual, t. II, México / Barcelona, Ballescá y Cía. Editores/Espasa y Cía. Editores, 1889.

RuEDAS DE LA SeRna, Jorge, “Presentación”, La misión del escritor. Ensayos mexicanos del siglo XIX, México, Universidad Nacional Autónoma de México- Coordinación de Humanidades (Ida y regreso al siglo XIX), 1996.

SALMERÓN MoRA, Arturo, "Las armas de la Ilustración: folletos, catecismos, cartillas y diccionarios en la construcción del México moderno", Empresa y cultura en tinta y papel (1800-1860), Laura Suárez de la Torre, coord. gral., Miguel Ángel Castro, ed., México, Instituto Mora/Universidad Nacional Autónoma de México, 2001.

VIGIL, José María, "Algunas observaciones sobre la literatura nacional", La misión del escritor. Ensayos mexicanos del siglo XIX, Jorge Ruedas de la Serna organización y presentación, México, Universidad Nacional Autónoma de México-Coordinación de Humanidades (Ida y regreso al siglo XIX), 1996.

, "Necesidad y conveniencia de estudiar la historia patria", Polémicas y ensayos mexicanos en torno a la historia, Juan A. Ortega y Medina, México, Universidad Nacional Autónoma de México-Instituto de Investigaciones Históricas (Serie Documental 8), 1992 (primera edición 1970).

WHIтE, Hayden, Metahistoria. La imaginación histórica en la Europa del siglo XIX, trad. Stella Mastrangelo, México, Fondo de Cultura Económica 
(Sección de Obras de Historia], 2001 [edición original en inglés 1973).

ZERMEÑo, Guillermo, La cultura moderna de la historia. Una aproximación teórica e historiográfica, México, El Colegio de México (Centro de Estudios Históricos), 2002.

Prieto, Guillermo, Obras Completas, Presentación Boris Rosen Jélomer, Prólogo Ernesto de la Torre Villar (t. XxvIII Lecciones de historia patria), México, Dirección General de Publicaciones del Consejo Nacional para la Cultura y las Artes, 1999, t. XXVIII.

HeMEROgrafía CITADA

Matute, Álvaro, "Notas sobre la historiografía positivista mexicana", Secuencia.

Revista de Historia y Ciencias Sociales, México, Instituto Mora, núm. 21, septiembre- diciembre 1991, 49-64.

PI-SUÑER, Antonia, "La generación de Vicente Riva Palacio y el quehacer historiográfico", Secuencia. Revista de Historia y Ciencias Sociales, México, Instituto Mora, núm. 35, mayo-agosto 1996, 83-108.

FeCHA DE RECEPCIÓN DEL ARTículo: 16 de julio de 2008

FECHA DE ACEPTACIÓN Y RECEPCIÓN DE LA VERSIÓN FINAL: 21 de diciembre de 2009 